\title{
The Erosion Prediction Impact on Current Hall Thruster Model Development
}

\author{
W. Ethan Eagle ${ }^{1}$ and Iain D. Boyd ${ }^{2}$ \\ University of Michigan, Ann Arbor, MI, 48109 \\ Samuel G. Trepp ${ }^{3}$ and Raymond J. Sedwick ${ }^{4}$ \\ University of Maryland, College Park, MD, 20742
}

\begin{abstract}
The past ten years have seen a rapid increase in interest in high specific impulse thrusters which can deliver very high payload mass fractions compared to chemical thrusters. One such choice, the Hall thruster, is gaining ground due to its relative simplicity and commercial availability. In order to accomplish high impulse missions however, these low thrust devices must successfully operate for thousands of hours. To help offset the enormous cost of extended ground testing, a variety of modeling efforts is underway. The goal of this paper is to overview the past and present of Hall thruster model development and to highlight three areas of research: improved sputtering models, uniform availability of magnetic field data and anomalously high electron mobility, which have each individually shown promise towards improving the predictive capability of these modeling efforts.
\end{abstract}

\section{Introduction and Background}

C INCE the first Hall thruster deployment on a US spacecraft in 1998 onboard the National Reconnaissance Office's Space Technology Experiment Satellite (STEX), Hall thrusters like the BPT-4000 [ Fig 5] have enjoyed a rapid increase in research interest from US sources. ${ }^{1}$ This success is the culmination of commercial, governmental and academic investment in electric propulsion technologies. Since 1998, more than 30 US spacecraft have flown with either Hall or ion thrusters. ${ }^{1}$ In all, over 200 Hall thrusters have been operated in space and their mission reliability has been high. This makes them an attractive alternative compared to ion thrusters because of their low cost and simple operation principle. These devices (both Hall and ion thrusters) are attractive alternatives to chemical thrusters. They deliver very high specific impulse (1000-4000s) reducing the required propellant mass. However to achieve the same mission $\Delta \mathrm{V}$, these devices require order of magnitude increases in operational time. As a result, thruster reliability is a primary concern.

The goal of this paper is to investigate the future of Hall thruster application ${ }^{2-5}$, and provide insight, based on analysis of previous work, into one of the key areas of ongoing research and development. First we discuss the major motivation behind extension of Hall thruster lifetime ${ }^{5}$ and the benefits simulation has over experimentation ${ }^{6}$. Then we compare and contrast the various approaches, be they empirical ${ }^{7-13}$, theoretical ${ }^{14-22}$, or a mixed method ${ }^{22-25}$, which over the past 15 years have yielded varying levels of success in comparison with data ${ }^{7-9}$. Finally we make recommendations for future projects and areas of improvement.

\section{Lifetime Limits: The Enabling Factor for Hall Thruster Missions}

Hall thrusters are being considered for many missions because their high specific impulse (Isp) delivers a larger payload mass fraction than a similar chemical rocket. This feature is especially critical on cost capped missions, where payload is limited by launch vehicle choice. ${ }^{1}$ Any electric propulsion device relies on three primary attributes: propellant availability, power and device robustness. If we consider that propellant feed systems developed for other space applications have sufficient reliability and that we are operating at less than 2 AU where power available via solar collection meets systems requirements, then the lifetime of the device will be the factor which limits Hall thruster mission suitability.

The lifetime of these devices come into play for a simple reason. To Achieve the same DV in a high specific impulse thruster, a lowered mass flow exits at much higher velocity which reduces the thrust delivered per time and

\footnotetext{
${ }^{1}$ Graduate Research Assistant, Aerospace Engineering Department, 1320 Beal Avenue 2004 FXB Ann Arbor Michigan 48109, AIAA Student Member.

${ }^{2}$ Professor, Aerospace Engineering Department, AIAA Associate Fellow.

${ }^{3}$ Professional Masters Student, Aerospace Engineering Department, AIAA Student Member

${ }^{4}$ Assistant Professor, Aerospace Engineering Department, AIAA Senior Member.
}

American Institute of Aeronautics and Astronautics 092407 
increases the time the thruster must fire. A quick calculation reveals that a typical commercially available Hall thruster, a Busek BHT-600 (1500s ISP at $2.6 \mathrm{mg} / \mathrm{sec}$ propellant usage), must operate nearly 3700 hours to complete a 10 year geostationary absolute station keeping mission (an average of about $50 \mathrm{~m} / \mathrm{s}$ yearly for a $1000 \mathrm{~kg}$ satellite mass.) Current research has shown Hall thrusters are capable of delivering this length of operational life ${ }^{1}$. See Table 1. The challenge is thus to determine a systematic way the operational limit of these devices can be quantified.

\begin{tabular}{|l|c|c|c|c|}
\hline & \multicolumn{2}{|c|}{ Life Test Results (or Plans) } & \multicolumn{2}{c|}{$\begin{array}{c}\text { Usable Flight Limits } \\
\text { (50\% Margins) }\end{array}$} \\
\hline & $\begin{array}{c}\text { Throughput } \\
\text { (kg) }\end{array}$ & $\begin{array}{c}\text { Total Impulse } \\
\text { (MN-s) }\end{array}$ & $\begin{array}{c}\text { Throughput } \\
\text { (kg) }\end{array}$ & $\begin{array}{c}\text { Total } \\
\text { Impulse } \\
\text { (MN-s) }\end{array}$ \\
\hline NSTAR & 235 & 7.2 & 157 & 4.8 \\
\hline BPT-4000 - 5,800 h Life Test & 250 & 4.9 & 167 & 3.3 \\
\hline BPT-4000 - Phase One Extension & 274 & 5.3 & 183 & 3.5 \\
\hline BPT-4000 - Phase Two Extension & 426 & 7.7 & 284 & 5.1 \\
\hline
\end{tabular}

Table 1 Total impulse capabilities of NSTAR ion vs BPT-4000 Hall thruster for different operational lifetimes ${ }^{1}$

The primary cause of limited lifetimes in Hall thrusters is the ion impingement on the insulator at the exit of the thruster $^{5}$. Erosion changes discharge chamber geometry which results in overall operation change. Main thruster parameters such as efficiency and thrust also change over time. This could potentially result in the thruster no longer meeting mission requirements. This erosion of acceleration channel wall material occurs continually until softer components or magnetic field coils are exposed and fail. The effects of erosion are also seen elsewhere in spacecraft integration where the high divergence angle of Hall thrusters makes the deposition of sputtered material a concern.

\section{Design and Testing Implications}

Devices used for spaceflight are flight qualified to operate based on a mean time to failure. However, consider that modern space technology is being pressured to meet the challenge of providing 10-15 year spacecraft life. Then to qualify even 5 thrusters to assess a mean, using 10 years as a lower bound, is 18,500 hours of earthbound thruster operation. In addition to the huge time effort involved, the facilities cost to operate a Hall thruster must also be considered. For a typical thrust chamber to accurately simulate operational conditions, cryogenic pumps are used to remove the atmosphere from the test chamber. The cost of this equipment is astronomical, at roughly $1 \$ / \mathrm{Liter} / \mathrm{s}$ and a required evacuation rate of nearly $20 \times 10^{6} \mathrm{~L} / \mathrm{s}$, this translates to roughly $\$ 20 \mathrm{M}$ in facilities cost. ${ }^{6}$ Consider also that the common propellant choice for Hall thrusters is xenon, which at $\$ 1140 / \mathrm{kg}$ means that to ground test 5 thrusters for the $5 \mathrm{MN}-\mathrm{s}$ mission from Table 1 at $50 \%$ flight margin requires nearly $500 \mathrm{~kg}$ per thruster, or more than $\$ 2,500,000$ just in material cost. Current testing of Hall thrusters is limited by this extra-longevity and expense and hence testing of multiple devices to determine average life is simply intractable. Therefore, it is necessary to validate device lifetime by demonstration tests of a single model. Unfortunately, as required operation time increases, validation of true lifetime from a single sample becomes at best, usefully inaccurate, in that some thruster data is certainly useful, but the question remains how one can draw valid conclusions from a single data point.

NASA reliability requirements indicate that these lifetimes must be validated and extended before further acceptance and incorporation into future space missions takes place. Some key variables affecting the lifetime of these devices have been discovered. Higher powered thrusters unsurprisingly erode more quickly ${ }^{7,9}$. However, clever magnetic confinement ${ }^{16}$ and channel wall materials choice ${ }^{9}$ can enhance thruster longevity. Unfortunately none of these efforts have shown considerable improvements. Key questions remain regarding unusually high electron mobility ${ }^{17}$ within these devices. The work begun to evaluate these commercial thrusters has shown promise, however many believe that a much more cost effective step would be to use computational modeling as an alternative.

\section{Current Erosion Research Efforts}

Current methodology is focused in 3 areas. Empirical modeling is essentially using predictions based on actual device erosion over short time scales to extrapolate erosion for all time. Semi-empirical modeling relies on data collected from 'fundamental' experiments and attempts to explain the erosion behavior based on several variable parameters. The last, and most computationally intensive are the theoretical models which use fundamental physical principles to directly simulate thruster operation to predict erosion. 


\section{A. Empirical Methods}

The first approach developed to predict erosion profiles, empirical methods were an obvious choice when little computing power was available and information was needed about thruster erosion. However, these models were usually only applicable for a single fixed configuration. The earliest measurements of erosion were fairly unsophisticated $^{7}$. Photographic images of the thruster were compared, so that data could be evaluated. The only available erosion data presented for the SPT-100 thruster is based off of two separate experiments ${ }^{7,8}$ which compare favorably to one another in Fig 1.

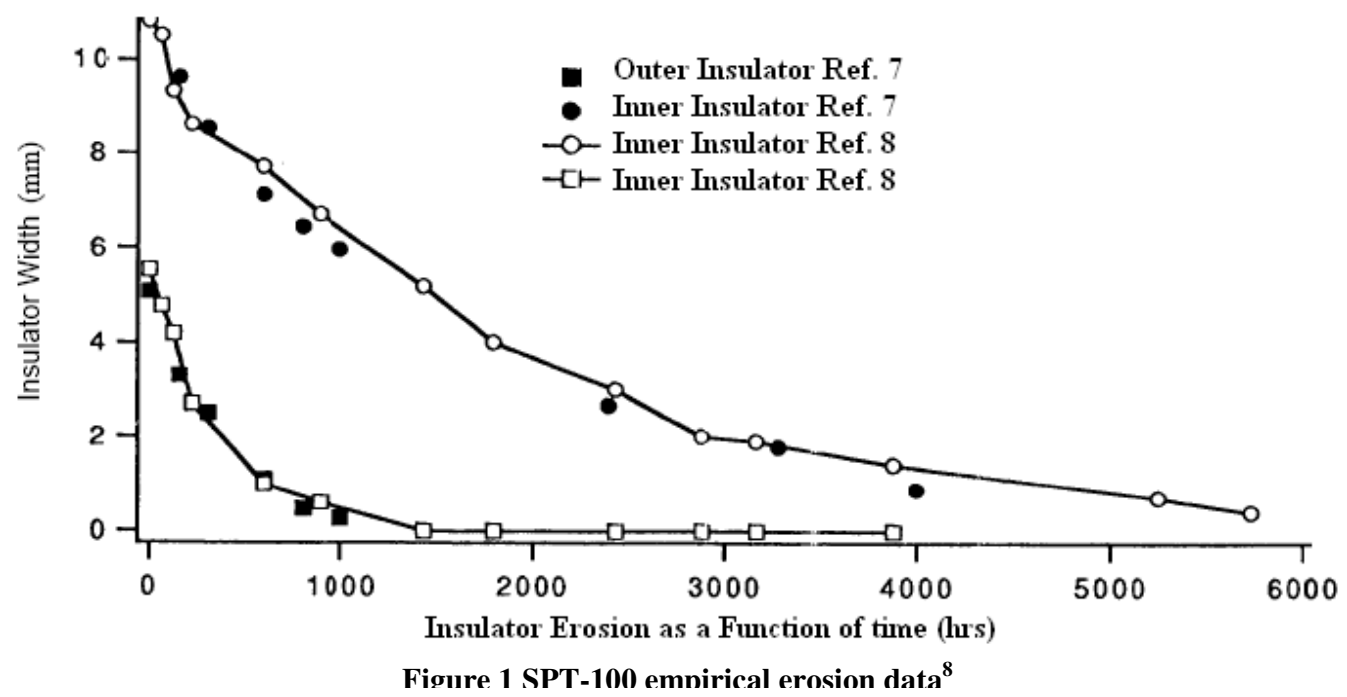

Measurements of erosion at one thruster size and power level are used to predict via scaling arguments lifetimes for accelerators with similar geometry, but different size and power. Using this one substantial time investment allows the Fakel team to establish lifetimes (see Fig 2) for the remainder of the SPT family ${ }^{10}$.

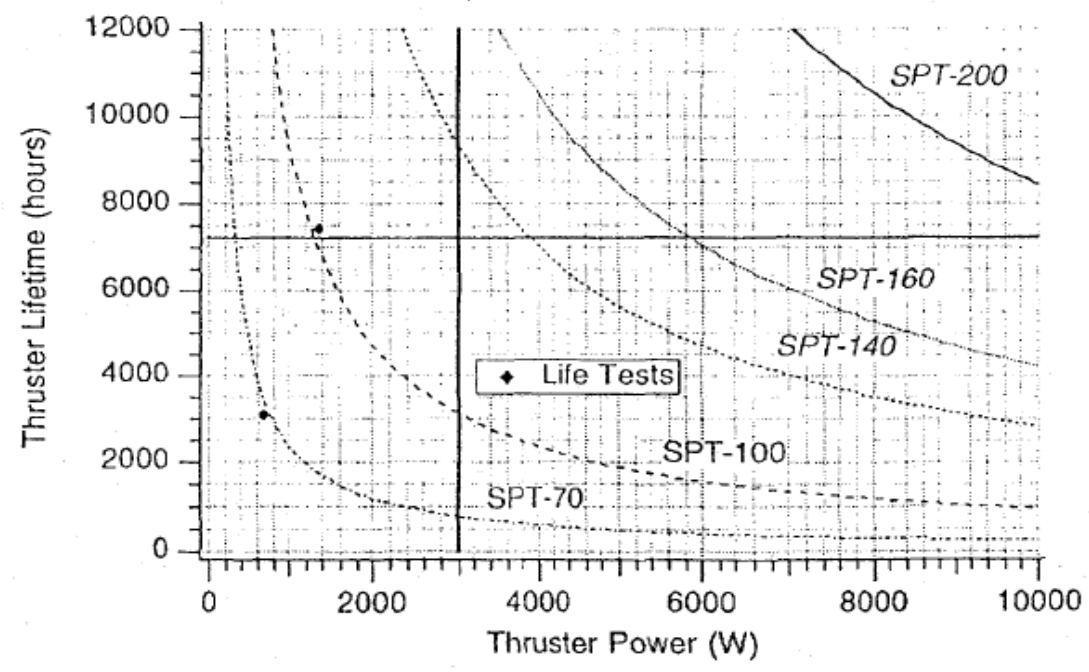

Figure 2 SPT family lifetime predictions based on scaling arguments ${ }^{10}$

The large amount of experimental data allows for establishment of reasonable empirical dependences. These dependencies are limited to yielding accurate results for similar devices only.

More recent experimentation ${ }^{1,11-13}$ has also taken place, using laser profilometry ${ }^{11}$ to more accurately measure eroded profiles, or using a novel spectrographic measurement of the Hall thruster plume to directly measure erosion rates $^{13}$. See Fig 3. These new techniques offer new ways to improve existing modeling techniques by providing more complete data sets. However, these tests were run for a maximum of $200 \mathrm{hrs,} \mathrm{and} \mathrm{were} \mathrm{primarily} \mathrm{focused} \mathrm{on}$ other experimental aspects. In the first case, tests were run to determine which of a series of wall material 
impregnations would yield the lowest erosion rate. The findings: a boron-nitride wall with a $6 \%$ concentration of boron-oxide was the most wear resistant. It also showed a negative correlation between magnetic field strength at the thruster exit and erosion rate on the inner wall, and a positive correlation with the erosion rate of the outer wall.

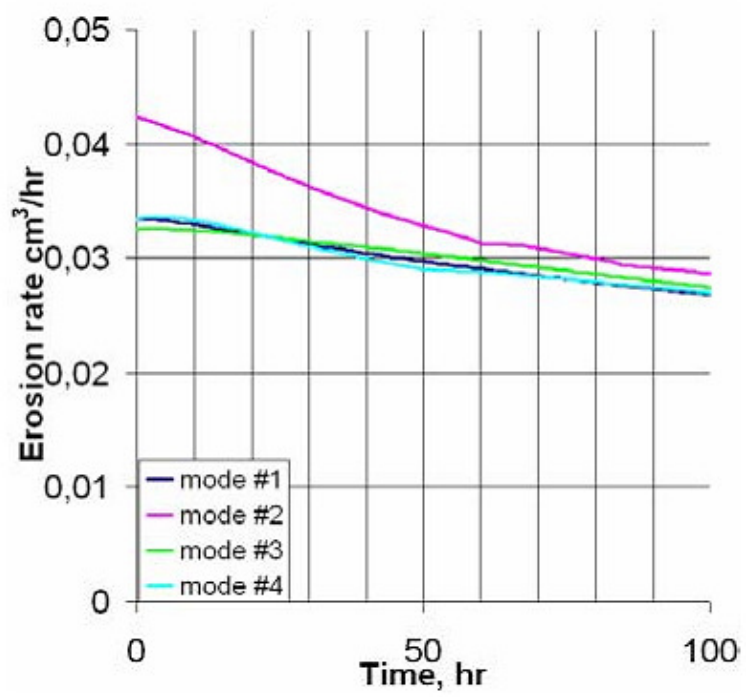

Figure 3 The dependence of erosion rate based on magnetic topology and operational hour ${ }^{13}$

Lifetime testing continues to occur at NASA to flight qualify Hall thrusters for future missions. High power thrusters which are expanding the flight envelope beyond GEO station-keeping are currently being tested ${ }^{1,12}$. Preliminary results show significant erosion, but good overall tolerance. See Fig 4. ${ }^{1}$ This continued testing remains important as empirical models especially benefit from more complete data, while other models can use erosion data to benchmark their simulations. However, even this new data is relatively sparse compared to what is needed for a complete validation of any empirical methods because any empirical analysis loses validity after changing the thruster's operation mode or physical construction. Hence work on strictly empirical methods has slowed, while research into the other two areas has continued to expand.

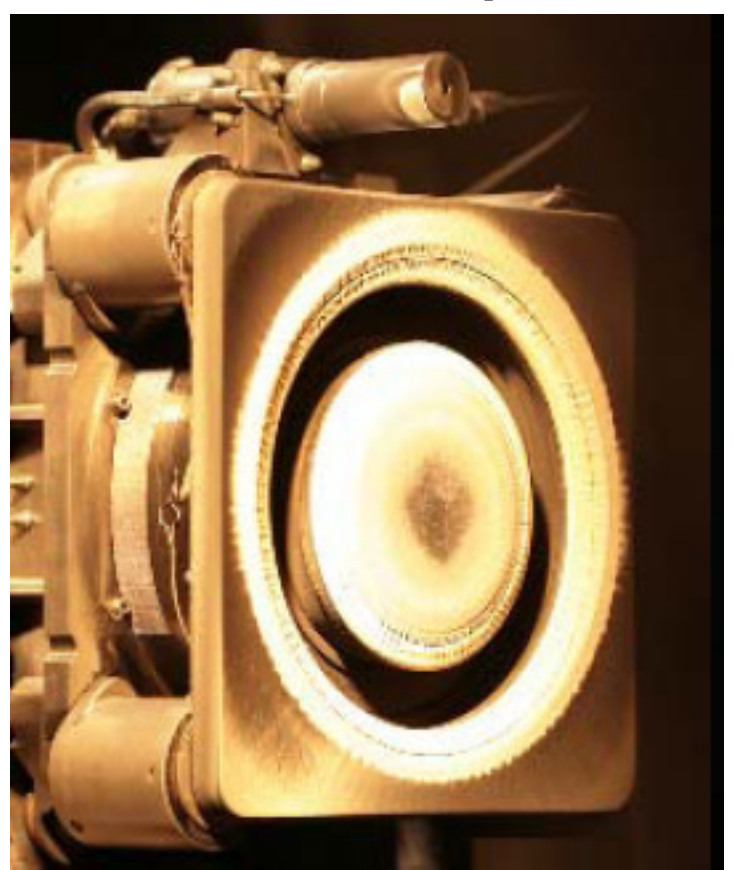

Figure 4 BPT-4000 showing 5800 hours of wear ${ }^{1}$ 


\section{B. Theoretical Methods}

Unlike empirical models, which are dependent on experimental data, theoretical methods rely on using physicsbased models to calculate ion flux by the methods described below. From the angle of incidence of the particle with respect to the wall surface, the particle characteristic energy, and a 'sputtering yield' (available via a variety of methods) for the wall material, the erosion rate at different points on the thruster can be determined and used to calculate wear. The various approaches are described in detail below.

\section{Ion flux calculations by the Particle in Cell (PIC) Method}

The most prevalent method of calculating plasma parameters in a Hall thruster is called the 'Particle in Cell' (PIC) approach. Alternately devised in the US $^{26,27}$ circa 1997 and in France ${ }^{14,15}$ circa 2002 these are twodimensional simulations of both the plasma in the thruster and subsequently the erosion caused. Using this method, the electrons are treated as a quasi-one-dimensional fluid governed by a generalized Ohm's law, and the ions and neutrals are described as discrete particles advanced in space using a PIC approach. After initializing the device using either a theoretically calculated ${ }^{14,16,17}$ or experimentally determined ${ }^{15,18,19}$ magnetic field distribution, the code can be run, with each calculation currently taking about a day on a desktop machine. Each model incorporates increasingly complex physical phenomena, from the simplest, which only considers singly charged ion species and charge/momentum exchange collisions ${ }^{14}$, enforcement of the Bohm conditions in the sheath ${ }^{15}$, heavy particle injection velocity ${ }^{16}$, and higher than expected electron mobility ${ }^{16-19}$. During each step, the plasma parameters throughout the thrust chamber are calculated, and the main component necessary to evaluate erosion, the fluxes and energy of the ion and neutrals hitting the wall, can be extracted. Using these distributions and making some assumptions about the way that the wall material sputters, (for typical BN wall material the accepted threshold value is about 50eV) the erosion, Figs. 4 and 5, or erosion rates, Figs. 6 and 7, can be calculated. The erosion is captured at each step and the wall boundaries are updated at a specific interval (usually once per 5\% of the total runtime), allowing the plasma to then adjust with the changing thrust chamber area.
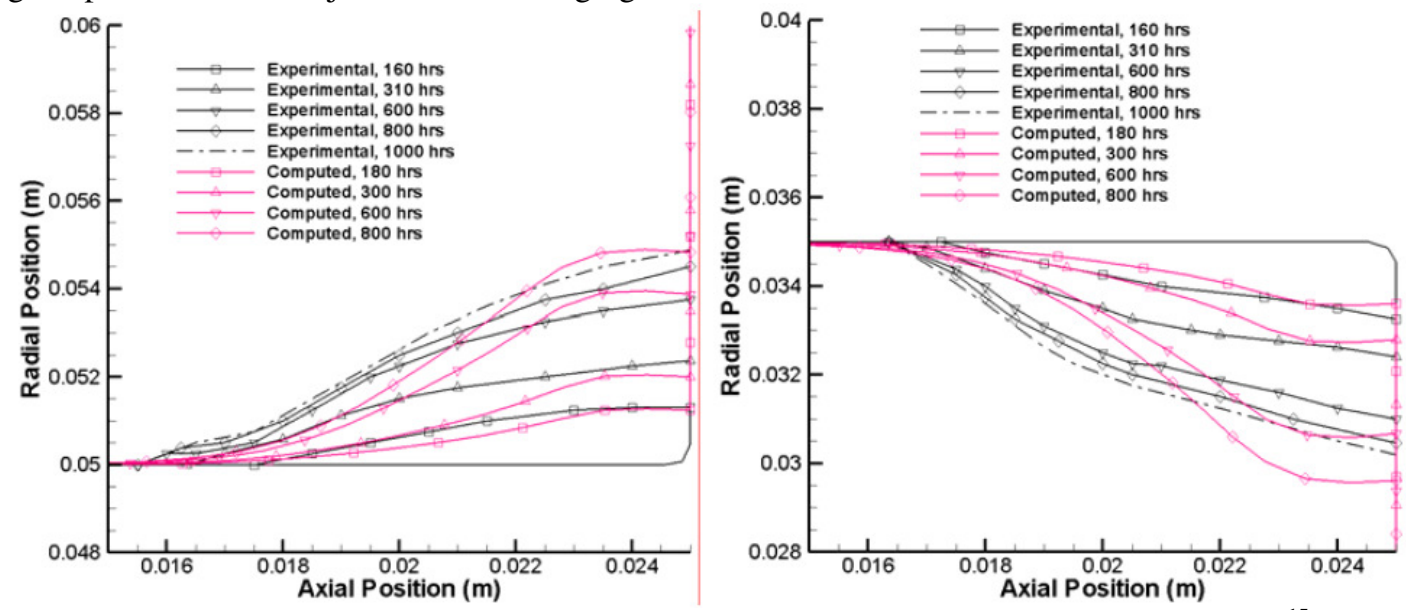

Figure 5 Outer and inner wall erosion profile (over predicted) vs experiment (SPT-100) ${ }^{15}$
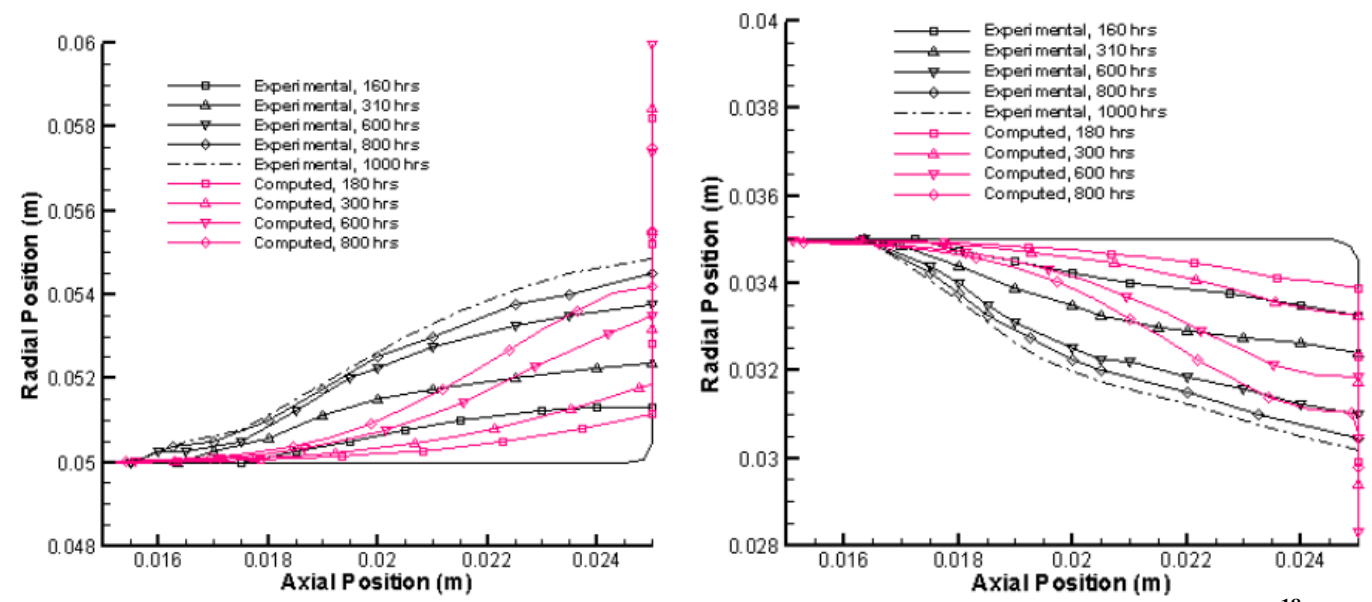

Figure 6 Outer and inner wall erosion profile (under predicted) vs experiment (SPT-100) ${ }^{18}$

$$
5
$$

American Institute of Aeronautics and Astronautics 

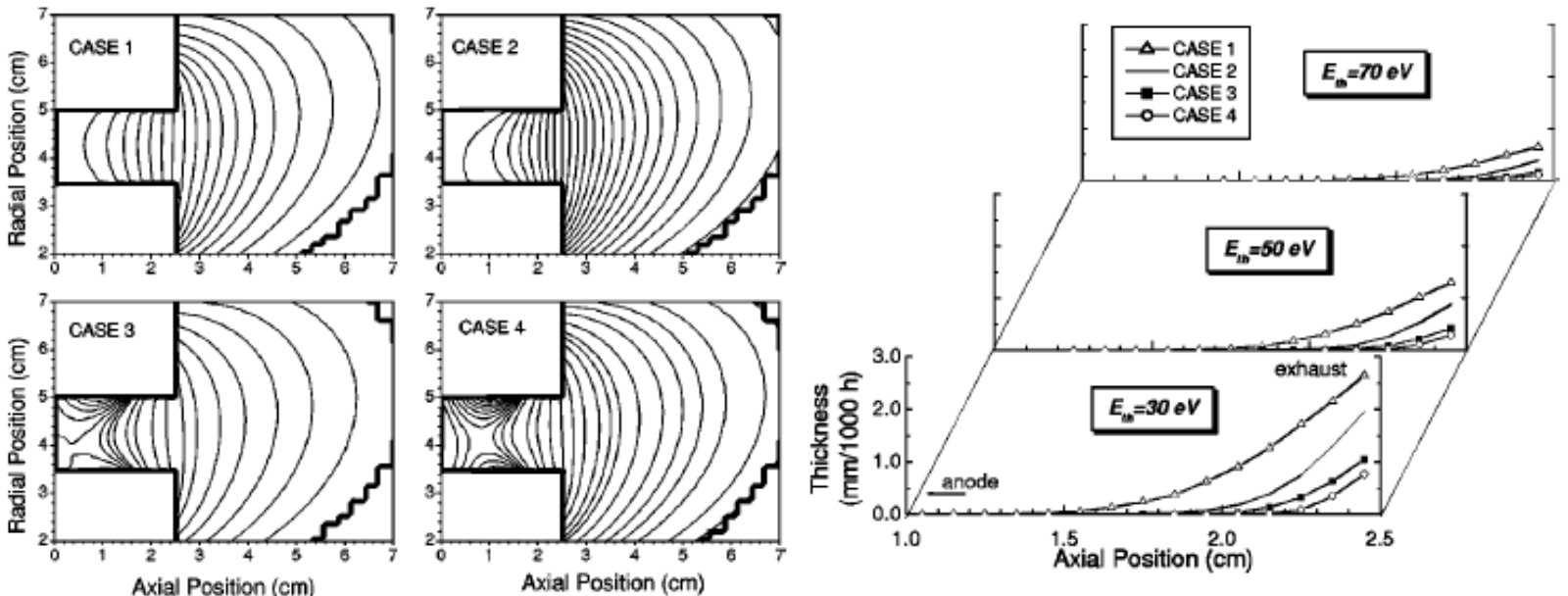

Figure 7 Magnetic field profiles and corresponding erosion rates for 3 separate threshold energies for 4 different magnetic field configurations of an SPT-100 ${ }^{17}$
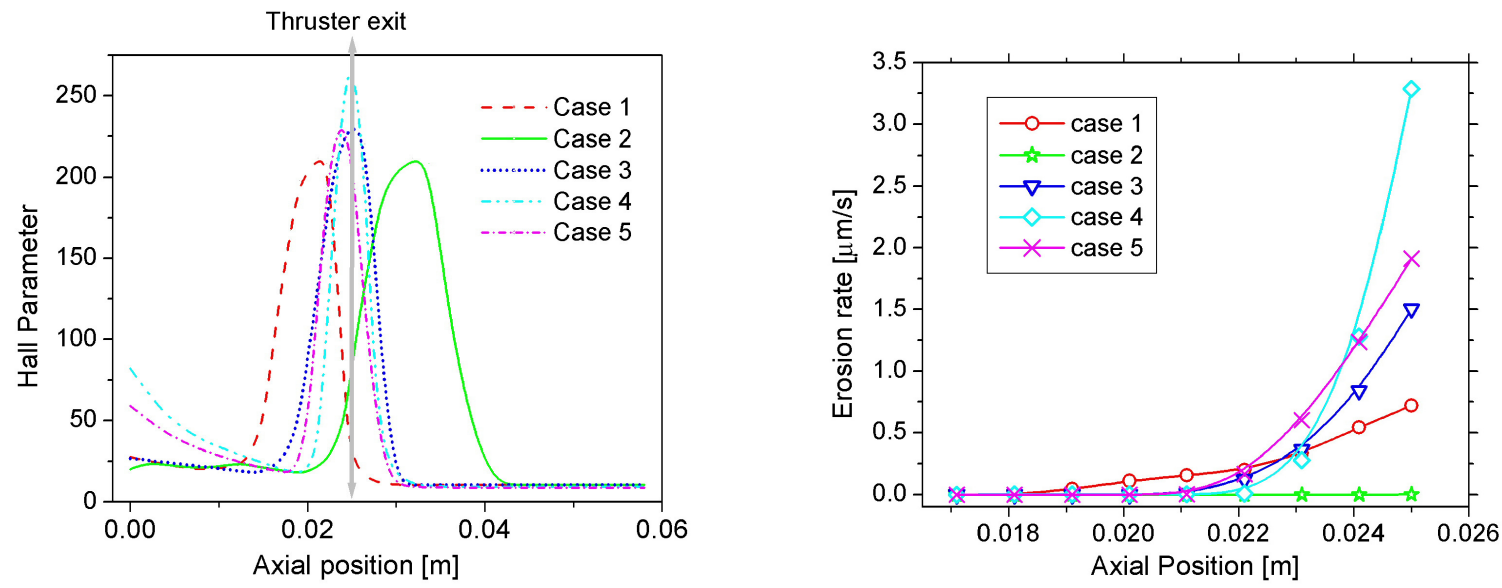

Figure 8 Variations in Hall parameter and subsequent changes in erosion rate of the outer wall ${ }^{14}$

As can be seen, these models show consistency among the different approaches. However, as shown, the dependence of erosion rate on magnetic field profile makes any quantitative comparison impossible. The primary issue is the lack of published data on the 2-dimensional magnetic field profiles inside of the SPT-100 due to its proprietary nature. Errors in each model are attributed to the lack of measurement data of how the changing thruster geometry affects the magnetic field profile. Further uncertainty is explained by the difference in sputter yield curve fitting. Low energy sputtering has yet to be described accurately for the ceramic wall material used in these thrusters. As a result, assumptions made regarding the threshold energy for sputtering cause large variations among model predictions ${ }^{17}$, as in Fig 7. Another serious challenge encountered by these models is the anomalously high electron mobility, which is currently unexplained by collision rates with atoms and the walls. In order to match measured values, models ${ }^{16-19}$ insert an additional electron mobility parameter, which acts to artificially increase the mobility until it reaches a value that matches well with experiment. This is arguably no better than performing an empirical fit.

These methods have reached a useful level of fidelity for the thrusters which they are tweaked to match. Questions arise however, as to how well they continue to fair when their input parameters are changed. None of the currently published papers show the ability to run over a large set of operational conditions, either because the data for such conditions do not exist to compare against, or because the models only converge for some small subset of the available data. Assuming they are capable of converging for many input conditions, it would be time consuming to evaluate a matrix of input conditions which would help determine an optimum design state. However, a separate method is available which has shown promise and considerably shortened computational time.

American Institute of Aeronautics and Astronautics 092407 
2. Ion flux calculations by the Molecular - Hydrodynamic (MHD) Method

The Molecular-Hydrodynamic approach was devised by Boyd and Yim ${ }^{20-22}$ as an attempt to achieve better results more quickly than PIC methods by increasing the fidelity of the sputtering model ${ }^{22}$ while simultaneously simplifying the underlying plasma physics ${ }^{20}$. Compared to the PIC codes, the hydrodynamic model offers a fairly quick computational analysis, on the order of minutes rather than days. This may seem somewhat unintuitive as a molecular dynamics simulation is typically as computationally expensive as a PIC method; however, it is only necessary to calculate the sputter yields once. ${ }^{22}$ The hydrodynamic model uses the same fluid model for electrons as the PIC method, but also uses a fluid analog for the ions and neutrals. The results from early modeling ${ }^{20}$ were quite promising. See Figs. 9 and 10. While again qualitatively interesting, the shapes of these profiles did not match well with experiment.

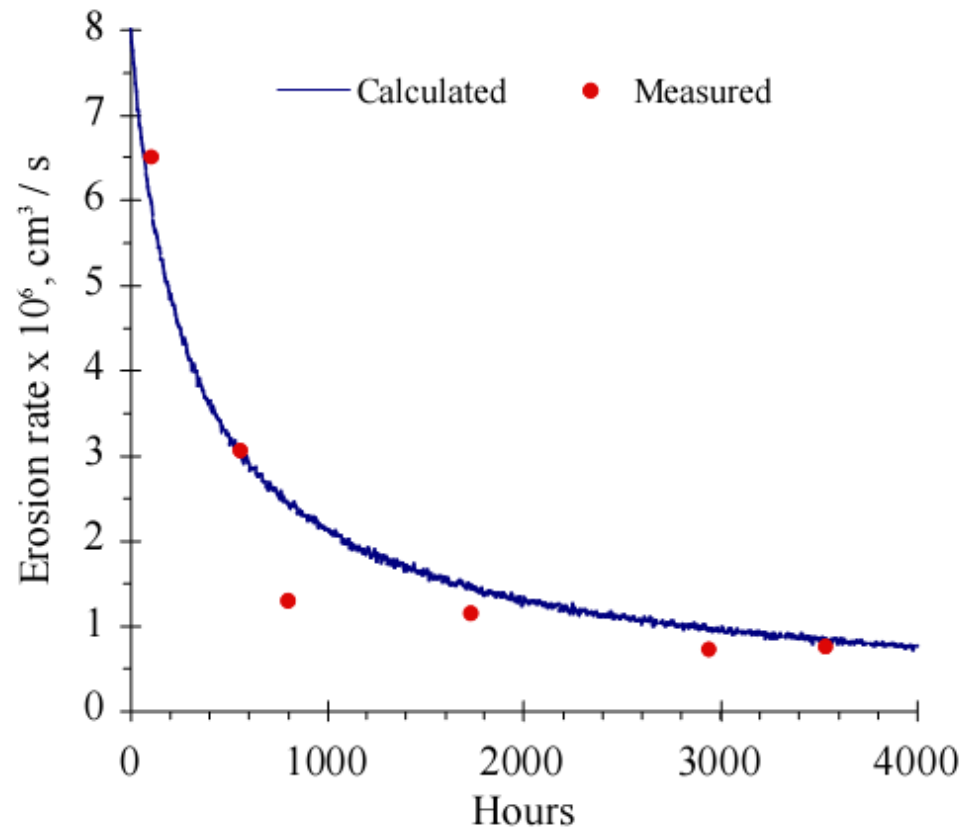

Figure 10 Volumetric erosion rate as a function of time ${ }^{20}$
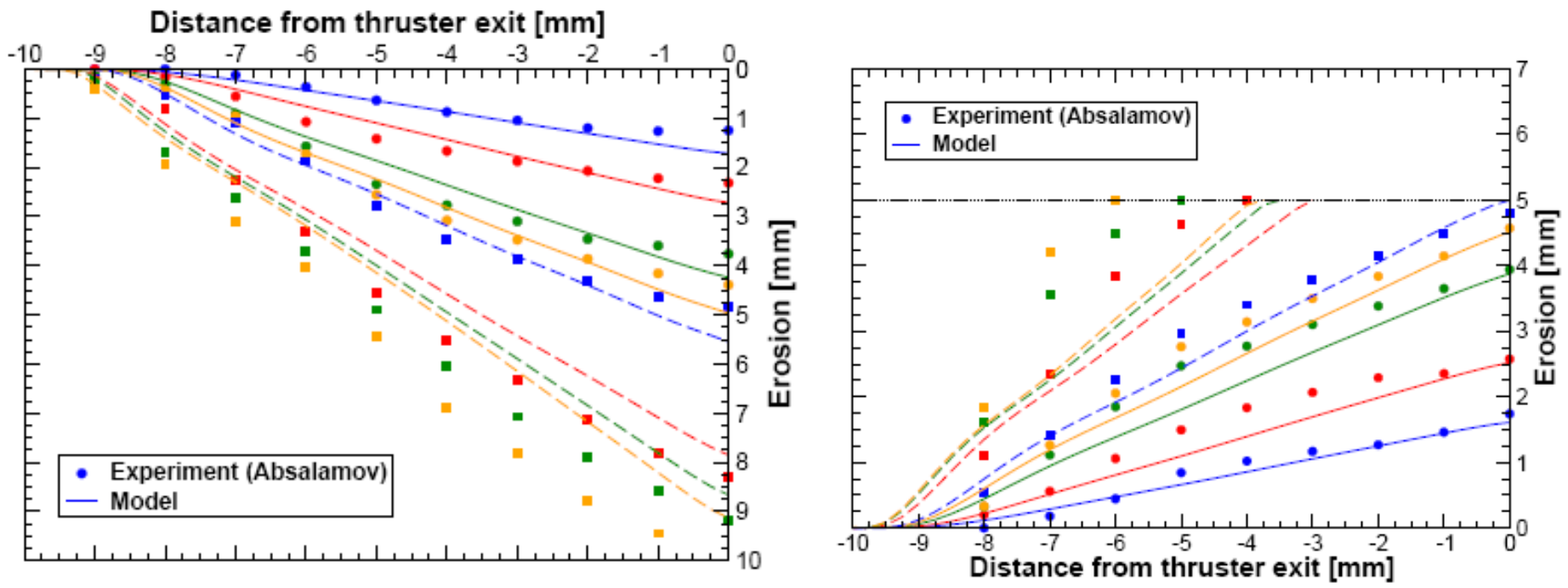

Figure 9 Inner and outer erosion profiles for SPT-100 from 100 to $4000 \mathrm{hrs}^{21}$

American Institute of Aeronautics and Astronautics 
The factors which affect the PIC methods also have a significant impact on the hydrodynamic model. The key factors are again the anomalous electron mobility, interior magnetic field contours, and sputter yield model, specifically near the sputtering energy threshold. The final model incorporates, rather than an empirical fit, the first physics based calculations of sputter. ${ }^{22}$ The resulting erosion profile shapes (see Fig. 11) are the most promising of the theoretical models thus far.

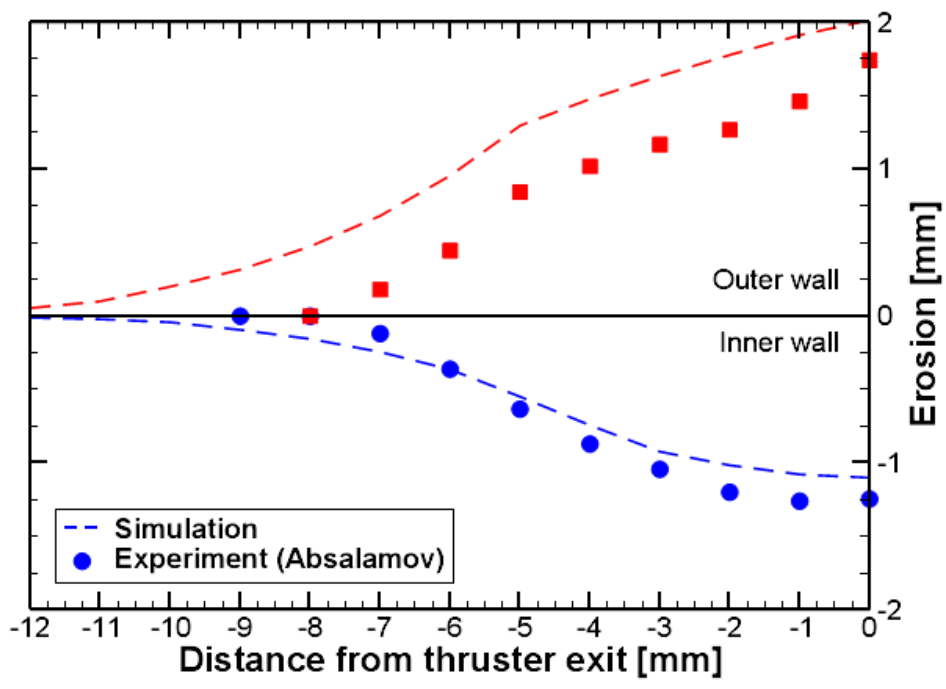

Figure 11 A qualitative comparison of the calculated beginning of life erosion profile after 160 hours $^{22}$

Each theoretical model incorporates a level of empiricism just below the surface. The 'tweaks' like the electron mobility can be motivated by a lack of physical insight into the true dynamics of these thrusters. This has inspired some methods to bridge the gap between the theoretical and the empirical; abandoning theoretical models where insufficient physics describe the known data, abandoning the empirical when physics and data are in good agreement.

\section{Semi-Empirical Methods}

Primarily occurring in Russia, the main development bed of Hall thrusters during the 1970's and 1980's, the semi-empirical methods are used to accelerate the lifetime testing of operational thrusters ${ }^{24}$. By using computational methods which match well with the beginning of life data taken from the thruster, this method is used to calculate an eroded profile near the 1000 hour operation point. The thruster is then run afterwards to determine the decreased erosion rate in the long life stabilization region noted in both experimental and theoretical methods. This method of testing reduces necessary experimental test time to one fifth the pure empirical methods. Semi-empirical methods benefit because they avoid the uncertainty factors in laws of sputtering and ion flow distribution since they directly reference experimental data for that thruster. A full model of erosion can then be built to curve-fit the data collected on the erosion rates from the simplified experimental setups. Comparison of this type of model ${ }^{25}$ to true full lifetime test runs has thus far proven highly successful. See Figs. 12 and 13. 

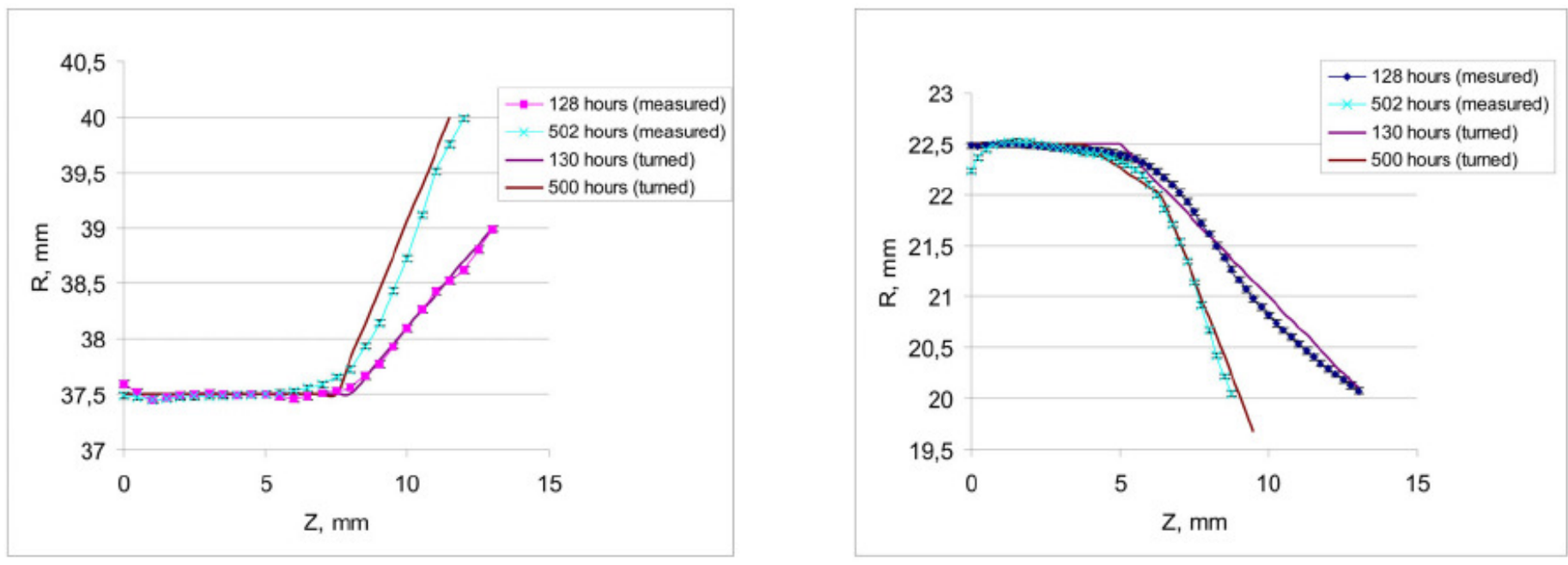

Figure 12 Outer and inner wall erosion profiles vs semi-empirical(turned) model $^{25}$
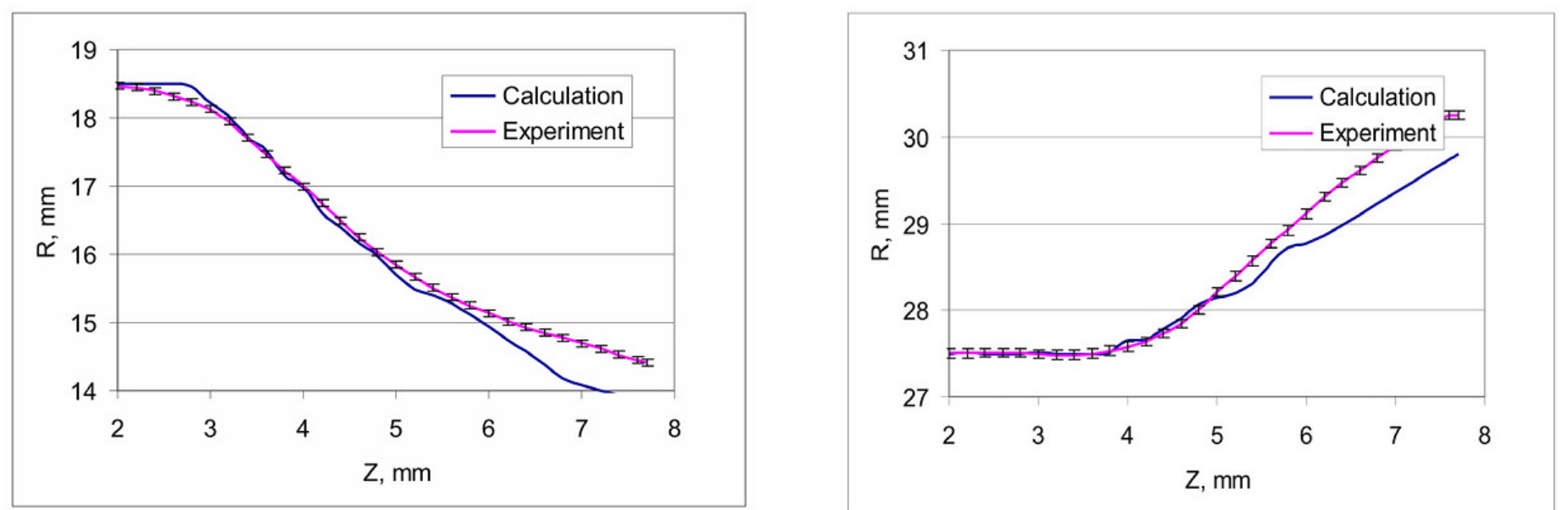

Figure 13 Semi-empirical erosion model vs collected data on interior and exterior insulator at 1020 hours of operation $^{25}$

During operational testing, direct measurement of the erosion rate is also possible by spectrographic means ${ }^{23}$. This method, should it be validated as accurate, would enable data collection which could directly validate many of the theoretical models. However, current data only exists for TAL type thrusters, and work in this area appeared to end in 2001.

\section{Conclusions}

Many of the Hall thruster lifetime models addressed thus far have shown considerable promise in one or more areas of prediction. However, anomalous erosion behavior in lifetime tests of greater than 2000 hours has yet to be addressed. Models correctly predict that the insulator walls begin to accommodate the ion flow structure resulting in a reduction in the erosion rate due to a reduction in plasma density and potential drop across the exit face of the thruster as erosion occurs. Shown in Fig 13, a 3 dimensional effect is also occurring. ${ }^{3}$ Grooves on the order of the cyclotron radius appear in the channel walls. Current 2-d simulations are incapable of capturing this affect. 

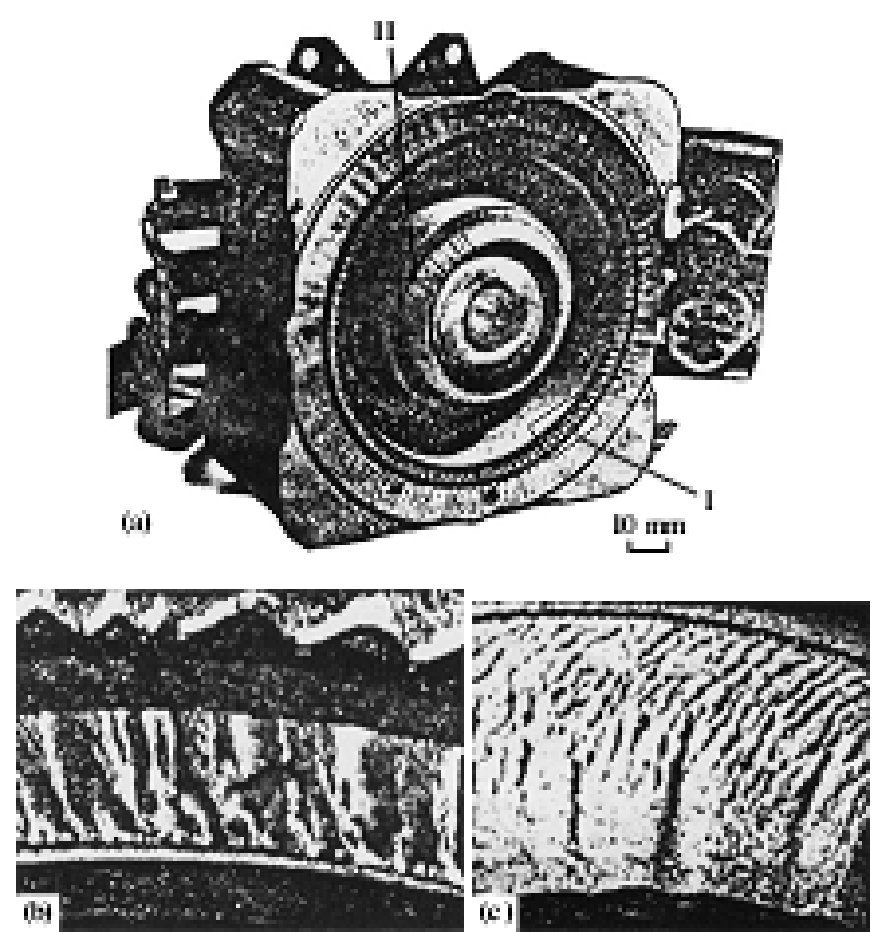

Figure 14 Erosion of the M-100 SPT after a 5000-h lifetime test: (a) a general view of the thruster, (b) an enlarged photo of fragment I of the outer insulator, and (c) an enlarged photo of fragment II of the inner insulator. ${ }^{3}$

Modeling efforts continue in all regimes, with continued lifetime testing of many different thrusters ongoing. Theoretical models like HPHall ${ }^{19}$ continue to be improved with increasing physical fidelity. As data from the most recent lifetime tests becomes available, a more complete assessment of these models will be possible if several key hurdles are overcome. ${ }^{28}$

The most challenging is identifying a clear physical description for the larger than expected electron mobility. This may potentially be solved by moving from 2D to 3D simulation, allowing for 3D 'relief' to enable enhanced electron motion. Until such theory can be developed, a unified approach, rather than resorting to arbitrary coefficients ${ }^{28}$ is necessary. Furthermore, precise experimental measurements of each thruster's electron mobility will be needed so that the correct tuning can be achieved.

A second problem facing modelers at present is the proprietary nature of the magnetic field data obtained during tests of commercial Hall thrusters. Due to the sensitivity of all methods of modeling to changes in magnetic field, a standard must also be implemented if quantitative comparisons are to be made. Current methodology uses thrust and current level as metrics for success for plasma simulation ${ }^{28}$, but this is little guarantee that the correct distribution of ions and neutrals are being represented inside the acceleration region. Quantification of the plasma simulation in these internal regions would further help validate erosion data.

The final challenge to be addressed lies in correctly evaluating the low ion energy sputtering process. While some significant progress has been started with the molecular dynamics approach developed by Boyd and Yim ${ }^{22}$, continued analysis and validation is necessary. Assessment of the absolute sputter yield would resolve much of the uncertainty currently seen in these models.

The future of Hall thruster life testing is, unsurprisingly, firmly entrenched between modeling and experimental validation. Just as computational codes will never fully supplant wind tunnel testing of modern aircraft, it is unlikely that full scale testing of Hall thrusters will ever cease. However, as with wind tunnel testing, the high cost (both time and money) associated with the qualification procedure suggests that a detailed modeling effort should continue to be undertaken, as it has been shown that its implementation reduces the experimental time required to generate long time-scale erosion predictions.

\section{Acknowledgements}

Part of this work was sponsored by NASA Glenn Research Center under grant NNX07AP25G. The first author would also like to thank his colleagues from Maryland for their support and encouragement. 


\section{References}

${ }^{1}$ Hofer, R. R., Randolph, T. M., Oh, D. Y., de Grys, K. H., Snyder, J. S., "Evaluation of a 4.5 kW Commercial Hall Thruster System for NASA Science Missions," $42^{\text {nd }}$ AIAA/SAE/ASME/ASEE Joint Propulsion Conference and Exhibit, July 2006, AIAA2006-4469.

${ }^{2}$ Gulczinski, F.S. and Spores, R.A., "Analysis of Hall-Effect Thrusters and Ion Engines for Orbit Transfer Missions," 32nd AIAA/SAE/ASME/ASEE Joint Propulsion Conference, July 1996, AIAA 96-2973.

${ }^{3}$ Morozov, A. I., "The Conceptual Development of Stationary Plasma Thrusters," Plasma Physics Reports, Vol. 29, No. 3, 2003, p. 235

${ }^{4}$ Jacobson, D. T., John, J., Manzella, D. H., Peterson, P. Y., “An Overview of Hall Thruster Development at NASA's John H. Glenn Research Center," $41^{\text {st }}$ AIAA/SAE/ASME/ASEE Joint Propulsion Conference and Exhibit, July 2005, AIAA-2005-4242.

${ }^{5}$ Gorshkov, O. Shagayda, A. and Muravlev, V. "The Experience of Hall Thruster Research and Development" $57^{\text {th }}$ International Astronautical Congress, 2006 IAC-06-C4.4.08.

${ }^{6}$ Kieckhafer, A., King, L. B., "Energetic of Propellant Options for High-Power Hall Thrusters," Journal of Propulsion and Power, Vol. 23, No. 1, 2007, p. 21.

${ }^{7}$ Abasalamov, S.K. et al., "Measurement of Plasma Parameters in the Stationary Plasma Thruster (SPT-100) Plume and Its Effect on Spacecraft Components," 28th AIAA/SAE/ASME/ASEE Joint Propulsion Conference, 1992, AIAA 92-3156

${ }^{8}$ Garner, Charles E; Brophy, John R; Polk, James E; Pless, Lewis C, "A 5730 Hr Cyclic Endurance Test of the SPT100" 31st AIAA/ASME/SAE/ASEE Joint Propulsion Conference and Exhibit, San Diego, CA, July 10-12, 1995 AIAA-1995-2667

${ }^{9}$ Arkhipov, B.; Bober, A.; Gnizdor R. et al., "The Results of 7000 hour SPT-100 Life Testing” Proceedings of the $24^{\text {th }}$ International Electric Propulsion Conference, Moscow, 1995, pp. 315-321

${ }^{10}$ Clauss,C.; Day,M.; Kim,V.; Kondakov,Y, and Randolph,T. "Preliminary Study of Possibility to Ensure Large Enough Lifetime of SPT Operating Under Increased Powers." 33rd AIAA/ASME/SAE/ASEE Joint Propulsion Conference and Exhibit, Seattle, WA, July, 1997 AIAA-1997-2789

${ }^{11}$ Peterson, P.Y., Manzella, D., "Investigation of the Erosion Characteristics of a Laboratory Hall Thruster," 39th AIAA/ASME/SAE/ASEE Joint Propulsion Conference, Huntsville, AL, July 2003 AIAA-03-5005.

${ }^{12}$ Welander, B., Carpenter, C., de Grys, K. H., Hofer, R. R., Randolph, T. M., Manzella, D. H., "Life and Operating Range Extension of the BPT-4000 Qualification Model Hall Thruster," 42nd AIAA/ASME/SAE/ASEE Joint Propulsion Conference, Sacramento, CA, July 2006, AIAA Paper 2006-5263.

${ }^{13}$ Dyshlyuk, E. N., Gorshkov, O. A., "Spectroscopic Investigation of a Hall Thruster Ceramic Acceleration Channel Erosion Rate," 42 ${ }^{\text {nd }}$ AIAA/SAE/ASME/ASEE Joint Propulsion Conference and Exhibit, Sacramento, CA, July 2006, AIAA-2006-4660.

${ }^{14}$ Sommier, E., Allis, M. K., Gason, N., and Cappelli, M. A., "Wall Erosion in 2D Hall Thruster Simulations," $42^{\text {nd }}$ AIAA/SAE/ASME/ASEE Joint Propulsion Conference and Exhibit, Sacramento, CA, July 2006, AIAA-2006-4656.

${ }^{15}$ Katz, I. and Gamero-Castano, M., "Estimation of Hall Thruster Erosion Using HPHall," $29^{\text {th }}$ International Electric Propulsion Conference, Oct. 2005, IPEC-2005-303.

${ }^{16}$ Duchemin, O., Dumazert, P., Carichon, S, Boniface, C., Garrigues, L., Baeuf, J., "Performance and Lifetime Predictions by Testing and Modeling for the PPS ${ }^{\circledR} 5000$ Hall Thruster," $39^{\text {th }}$ AIAA/SAE/ASME/ASEE Joint Propulsion Conference and Exhibit, July 2003, AIAA-2003-4555.

${ }^{17}$ Garrigues, L., Hagelaar, G. J. M., Bareilles, J., Boniface, C., et al., "Model Study of the Influence of the Magnetic Field Configuration on the Performance and Lifetime of a Hall Thruster," Physics of Plasmas, Vol.10, No. 12, pp. 4886-4892, 2003.

${ }^{18}$ Hofer, R. R., Katz, I., Mikellides, I. G., Gamero-Castano, M., "Heavy Particle Velocity and Electron Mobility Modeling in Hybrid-PIC Hall Thruster Simulations," $42^{\text {nd }}$ AIAA/SAE/ASME/ASEE Joint Propulsion Conference and Exhibit, July 2006, AIAA-2006-4658.

${ }^{19}$ Hofer, R. R., Mikellides, I.G., Katz, I., Goebel, D.M., "Wall Sheath and Electron Mobility Modeling in Hybrid-PIC Hall Thruster Simulations," 43 ${ }^{\text {nd }}$ AIAA/SAE/ASME/ASEE Joint Propulsion Conference and Exhibit, July 2007, AIAA-2007-5267.

${ }^{20}$ Manzella, D., Yim, J. T., Boyd, I. D., "Predicting Hall Thruster Operational Lifetime," $40^{\text {th }}$ AIAA/SAE/ASME/ASEE Joint Propulsion Conference and Exhibit, July 2004, AIAA-2004-3953.

${ }^{21}$ Yim, J. T., M. Keidar and I. D. Boyd, “An Investigation of Factors Involved in Hall Thruster Wall Erosion Modeling."42 $2^{\text {nd }}$ AIAA/ASME/SAE/ASEE Joint Propulsion Conference and Exhibit, Sacramento, CA, July 2006, AIAA-2006-4657.

${ }^{22}$ Yim, J. T., Boyd, I. D., and Keidar, M., "Hall Thruster Erosion Prediction Using A Hydrodynamic Plasma Model And Sputtering Simulation," $30^{\text {th }}$ International Electric Propulsion Conference, Sept. 2007, IPEC-2007-34.

${ }^{23}$ G.Karabadzhak, A. Semenkin, S.Tverdokhlebov, "Evaluation of a Xenon Operating Hall Thruster Body Erosion Rate Through Analysis of its Optical Spectra", 37th Joint Propulsion Conference, Salt Lake City, 2001, AIAA-2001-3889.

${ }^{24}$ Kim, V., Abgaryan, V., Kozlov, V., Skrylnikov, A., Jolivet, L., Prioul, M., "Development of the Accelerated Test Procedure for the SPT Discharge Chamber Wall Wearing During Long Thruster Operation," $39^{\text {th }}$ AIAA/SAE/ASME/ASEE Joint Propulsion Conference and Exhibit, July 2003, AIAA-2003-5003.

${ }^{25}$ Lovtsov, A., Shagayda, A., and Gorshkov, O., "Semi-Empirical Method of Hall Thrusters Lifetime Prediction," $42^{\text {nd }}$ AIAA/SAE/ASME/ASEE Joint Propulsion Conference and Exhibit, July 2006, AIAA-2006-4661.

${ }^{26}$ J. M. Fife, "Hybrid-PIC Modeling and Electrostatic Probe Survey of Hall Thrusters", Ph.D. Thesis, Massachusetts Institute of Technology, 1998

${ }^{27}$ Fernandez, E., Cappelli, M. A., Mahesh, K., “2D Simulations of Hall Thrusters,” CTR Annual Research Briefs, 1998

${ }^{28}$ S.Y.M. Cheng, "Modeling of Hall thruster lifetime and erosion mechanisms" Ph.D. Thesis, Massachusetts Institute of Technology, May 2007 